\title{
Long-Term Follow-Up Is Essential to Assess Outcome of Gastric Banding in Morbidly Obese Adolescents: A Retrospective Analysis
}

\author{
Givan F. Paulus $^{a, b} \quad$ Gerdy Konings $^{c} \quad$ Nicole D. Bouvy ${ }^{a}$ \\ L.W. Ernest van Heurn ${ }^{a}$ Jan Willem Greve ${ }^{d}$ \\ a Department of Surgery, Maastricht University Medical Center, and Nutrition and \\ Toxicology Research Institute (NUTRIM), Maastricht, the Netherlands; ${ }^{b}$ Department \\ of Surgery, Spaarne Gasthuis, Haarlem, the Netherlands; ${ }^{c}$ Department of Psychiatry \\ and Psychology, Maastricht University Medical Center, Maastricht, the Netherlands; \\ ${ }^{\mathrm{d}}$ Department of Surgery, Atrium Medical Center, Heerlen, the Netherlands
}

\section{Key Words}

Bariatric surgery - Laparoscopic gastric banding · Adolescents · Eating behavior · Personality

\begin{abstract}
Background: Adolescent obesity is rapidly becoming more prevalent and is associated with chronic health conditions and psychosocial morbidity. Lifestyle intervention is often ineffective in morbidly obese adolescents, and bariatric surgery is gradually becoming an accepted treatment. However, little is known about long-term results. Methods: Hospital charts of patients who had undergone gastric banding more than 5 years ago at an age of 18 years or younger, were retrospectively analyzed. Weight loss, complications, reoperations, and comorbidity reduction were assessed as well as health status, food behavior, and personality. $\boldsymbol{R e}$ sults: BMI loss in 10 adolescents was $10.7 \mathrm{~kg} / \mathrm{m}^{2}\left(-0.9\right.$ to $\left.12.9 \mathrm{~kg} / \mathrm{m}^{2}\right)$ after a median follow-up of 64 months (52-84 months); the major part of weight loss occurred after the first year. In 4 patients the gastric band was removed after 3.5-5.5 years. Two out of 3 patients effectively lost weight after conversion to a bypass type procedure. One patient is maintaining a stable healthy weight after band removal. Conclusions: Laparoscopic adjustable gastric banding in morbidly obese adolescents had a failure rate of $40 \%$, but was a successful therapy in the other $60 \%$ without major adverse events. Follow-up longer than 36 months was crucial for optimal evaluation of weight loss and reoperation rate.

(C) 2016 The Author(s)

Published by S. Karger GmbH, Freiburg
\end{abstract}


Paulus et al.: Long-Term Follow-Up Is Essential to Assess Outcome of Gastric Banding in Morbidly Obese Adolescents: A Retrospective Analysis

\section{Introduction}

An estimated $13.0 \%$ of US adolescents are currently morbidly obese; a number that has impressively tripled over the past decade [1]. Obesity is associated with chronic health conditions including type 2 diabetes mellitus, hypertension, dyslipidemia, obstructive sleep apnea syndrome, and osteoarthritis [2,3]. Furthermore, obese adolescents are likely to suffer from psychological morbidity, loss of self-esteem, and social exclusion [4]. Management of adolescent obesity is mostly focused at combined lifestyle intervention, initiated and coordinated by specialized pediatricians. While often effective in the short term, long-term effects are disappointing, especially in extreme obesity. A Cochrane review published in 2009 shows a maximum of $1.7 \mathrm{~kg} / \mathrm{m}^{2} \mathrm{BMI}$ loss after 12 months [5].

Bariatric surgery is becoming an accepted treatment for weight reduction in morbidly obese adolescents. Presently, three operative techniques are commonly used: laparoscopic adjustable gastric banding (LAGB), Roux-en-Y gastric bypass (RYGB), and laparoscopic sleeve gastrectomy. These techniques differ in excess weight loss, resolution of co-morbidity, quality of life improvement, and complication rate [6]. The short-term results are relatively well documented, but medium and long-term effects are largely unknown while studies in adults show that reoperation mostly occurs several years after bariatric surgery [7]. In our hospital LAGB was done in adolescents until 2008, when the Health Care Inspectorate (Inspectie voor de Gezondheidszorg; IGZ), based on a new national guideline on obesity, asked for more evidence-based practice and prohibited adolescent bariatric surgery. To assess the mediumterm results of LAGB we analyzed the outcome of 10 adolescents who underwent this procedure more than 5 years ago.

The aim of this study is to assess long-term weight loss, adverse events, comorbidity resolution, and health status in morbidly obese adolescents operated on before 2008. The secondary aim is to evaluate the available data on eating behavior and personality traits before and after surgery [8-11].

\section{Material and Methods}

The hospital registration system was queried for all patients aged 18 years or younger who had surgery coded as LAGB. All patients were operated in or before 2008, when the IGZ prohibited bariatric surgery in adolescents in non-research settings. The medical ethics committee of the Maastricht University Medical Center waived the acquisition of informed consent (METC 14-4-122).

Patients were eligible for surgery if non-surgical attempts to lose weight had failed and BMI was above $40 \mathrm{~kg} / \mathrm{m}^{2}$ or above $35 \mathrm{~kg} / \mathrm{m}^{2}$ with comorbidity. The procedure was not scheduled before the patient had been assessed by a medical psychologist, primed for the postoperative eating pattern by a dietician and discussed in the multidisciplinary team. The adjustable silicone gastric band (Lap-Band, INAMED Health, Santa Barbara, CA, USA) was placed via laparoscopy using pars flaccida technique in all subjects [12].

Bariatric surgery follow-up included frequent outpatient clinic visits in the first year after surgery and yearly afterwards. Weight loss, vital parameters, comorbidity resolution, and adverse events were evaluated at each visit. The surgeon and dietician evaluated eating pattern and weight loss, and the gastric band was adjusted when indicated. In the past year, all adolescent patients were asked to complete questionnaires to assess their health status, eating behavior, and personality. Data on weight loss, comorbidity, and complications were retrospectively collected from medical records. Weight loss is expressed as BMI loss and as excess BMI loss (a normal BMI corresponds to the age- and sex-adjusted equivalent of $25 \mathrm{~kg} / \mathrm{m}^{2}$ ) at the latest followup with gastric band in situ.

\section{Questionnaires}

Four validated questionnaires were used to assess health status, eating behavior and personality. The Dutch version of the Short Form 36 Health Survey (SF-36) was used to assess health status in eight domains. Raw scale scores of the SF-36 were transformed into standardized scores from 0 (the worst) to 100 (optimal) 
Paulus et al.: Long-Term Follow-Up Is Essential to Assess Outcome of Gastric Banding in Morbidly Obese Adolescents: A Retrospective Analysis

and compared to Dutch population reference values [13]. The Dutch Questionnaire of Eating Behavior (NVE) assesses eating behavior in three subscales: restrained eating, emotional eating, and external eating [14]. Subscale scores are compared to a Dutch normal-weight population in the graph [8]. The Eating Disorder Examination Questionnaire (EDE-Q) is a 36-item questionnaire to assess the psychopathology associated with the diagnosis of an eating disorder. It retains four subscales: restraint, eating concern, shape concern, and weight concern. Subscale sores are compared to international population references [15]. The Dutch Personality Questionnaire (NPV) assesses personality traits on seven scales: neuroticism, social anxiety, rigidity, hostility, egoism, dominance, and self-esteem [16]. Because the NPV is not validated under the age of 16 years, the junior version of the NPV (the NPV-J) was used for those who were younger in preoperative screening. It consists of five scales (of which three are identical to the scales on the adult version): neuroticism, perseverance, social anxiety, recalcitrance, and dominance [17]. All questionnaires, except for the SF-36, were also used during the preoperative screening.

Statistical Analysis

Statistical analysis was performed using Prism 6.0 (GraphPad Software, Inc. La Jolla, CA, USA) and SPSS 19.0 (IBM Corporation, Somers, NY, USA). Baseline data were compared with data acquired at the latest visit with the gastric band in situ or with data acquired at the last visit, when appropriate. When patients were lost to follow-up, their last known data were used as end of follow-up. Weight assessment parameters and questionnaire scores are reported as median (interquartile range, IQR). Data were tested with non-parametric Wilcoxon signed rank test, since Gaussian distribution cannot be assumed and missing data at 6 and 12 months impedes multiple comparisons. A p value $<0.05$ was considered statistically significant.

\section{Results}

\section{Weight Loss, Adverse Events, and Reoperations}

Ten adolescents were treated with gastric banding between July 2004 and August 2008. Seven patients visited our clinic in the past year, while the other 3 were lost to follow-up. The presented results represent all 10 patients at their latest follow-up visit. BMI loss with gastric band in situ was $10.7 \mathrm{~kg} / \mathrm{m}^{2}$ ( -0.9 to $12.9 \mathrm{~kg} / \mathrm{m}^{2}$ ) after a median follow-up of 64 months (52-84 months), corresponding to $63.7 \%$ ( -1.6 to $84.5 \%$ ) excess BMI loss (table 1, fig. 1). Six patients lost more than $50 \%$ excess BMI, one lost $41 \%$, and one lost $7 \%$ while 2 patients gained weight despite their gastric band ( $43 \%$ and $27 \%$ excess BMI, respectively).

Individual adverse events and re-operations are listed in table 1. Two subjects needed temporary desufflation of the gastric band; one for slippage and one for obstruction (after 2 and 3 years, respectively), after which their complaints resolved. In 4 out of 10 patients the band was removed.

One patient was treated in another bariatric surgery center for persistent referred pain in her left shoulder that resolved with removal of the gastric band. Conversion to biliopancreatic diversion (BPD) 3.5 years afterwards, because of weight regain, was uncomplicated and resulted in loss of $114 \%$ of her previous excess BMI. Two years after conversion to BPD this patient was hospitalized for inflammatory disease of the colon with unknown etiology.

A second patient had unexplained persistent sensations of dyspnea from postoperative day 1 that resolved with removal of the band 4.5 years later. She regained 10 of the $40 \mathrm{~kg}$ she had lost before, but had a stable weight without further intervention at the last visit, more than 1 year after band removal. A third patient regained 20 of the $35 \mathrm{~kg}$ she had lost before, when she underwent uncomplicated conversion to RYGB after 3.5 years and lost exactly $100 \%$ of her previous excess BMI. One year later she had an internal hernia that required laparoscopic repair (and revision 1 year later).

The fourth patient had her gastric band removed after 5.5 years because of weight regain and is now waiting for RYGB. 
Paulus et al.: Long-Term Follow-Up Is Essential to Assess Outcome of Gastric Banding

in Morbidly Obese Adolescents: A Retrospective Analysis

Table 1. Baseline characteristics, weight loss, adverse events and (re)operations

\begin{tabular}{|c|c|c|c|c|c|c|c|c|c|c|c|}
\hline \multirow[t]{2}{*}{ PID } & \multirow[t]{2}{*}{ Sex } & \multirow{2}{*}{$\begin{array}{l}\text { Age, } \\
\text { years }\end{array}$} & \multicolumn{4}{|c|}{ BMI, $\mathrm{kg} / \mathrm{m}^{2}$} & \multirow[t]{2}{*}{$\%$ EBMIL } & \multicolumn{2}{|c|}{ Follow-up, months } & \multirow{2}{*}{$\begin{array}{l}\text { Adverse events } \\
\text { (therapy) }\end{array}$} & \multirow{2}{*}{$\begin{array}{l}\text { Operation } \\
\text { (BMI at total** FU) }\end{array}$} \\
\hline & & & OR & $6 \mathrm{M}$ & $12 \mathrm{M}$ & end* & & LAGB* & Total** & & \\
\hline 1 & M & 15.3 & 38.0 & 34.6 & 33.9 & 27.6 & 82.1 & 104 & 104 & - & $\begin{array}{l}\text { mammoplasty; } \\
\text { revision mammoplasty }\end{array}$ \\
\hline 2 & M & 18.5 & 48.6 & 47.8 & 49.0 & 34.8 & 58.7 & 119 & 119 & - & - \\
\hline 3 & $\mathrm{~F}$ & 17.9 & 41.6 & 37.7 & 32.9 & 30.2 & 68.6 & 77 & 77 & - & tonsillectomy \\
\hline 4 & M & 16.9 & 46.2 & 45.1 & 42.4 & 45.3 & 6.8 & 59 & 59 & - & - \\
\hline 5 & $\mathrm{~F}$ & 16.9 & 39.6 & 38.7 & 36.2 & 46.2 & -42.7 & 41 & 85 & $\begin{array}{l}\text { referred shoulder pain } \\
\text { (band removal); weight } \\
\text { regain (BPD); intestinal } \\
\text { inflammation } \\
\text { (hospitalization); incisional } \\
\text { hernia (correction) }\end{array}$ & BPD (22.9) \\
\hline 6 & M & 14.9 & 37.0 & 33.1 & 31.3 & 26.1 & 91.7 & 71 & 71 & - & $\begin{array}{l}\text { mammoplasty; ptosis } \\
\text { correction }\end{array}$ \\
\hline 7 & $\mathrm{~F}$ & 16.2 & 44.7 & 40.3 & NA & 26.6 & 92.3 & 63 & 63 & - & $\begin{array}{l}\text { mammoplasty and } \\
\text { lower body lift } \\
\text { (complicated by } \\
\text { hematoma) }\end{array}$ \\
\hline 8 & $\mathrm{~F}$ & 16.7 & 43.0 & 34.4 & NA & 30.5 & 70.4 & 55 & 73 & $\begin{array}{l}\text { persistent dyspnea } \\
\text { (band removal) }\end{array}$ & band removal (34.0) \\
\hline 9 & $\mathrm{~F}$ & 16.7 & 39.9 & NA & NA & 34.1 & 41.2 & 44 & 73 & $\begin{array}{l}\text { obstruction (desufflation/ } \\
\text { re-insufflation); weight } \\
\text { regain (RYGB); internal } \\
\text { hernia after RYGB (repair } \\
\text { and re-repair) }\end{array}$ & RYGB (25.0) \\
\hline 10 & $\mathrm{~F}$ & 14.7 & 51.0 & NA & NA & 59.6 & -26.7 & 64 & 64 & $\begin{array}{l}\text { slippage (desufflation / } \\
\text { re-insufflation) }\end{array}$ & band removal (59.6) \\
\hline
\end{tabular}

6M = 6 months; $12 \mathrm{M}=12$ months; BPD = biliopancreatic diversion; RYGB = Roux-en-Y gastric bypass; NA = not available.

*End of follow-up with in situ gastric band.

**End of follow-up after re-operation (when applicable).

Other surgical procedures included: mammoplasty in 2 males and 1 female (combined with lower body lift) and an incisional hernia after BPD. One male patient is currently consulting a plastic surgeon for mammoplasty and lower body lift.

\section{Comorbidity}

Existing preoperative comorbidity was mostly limited to musculoskeletal complaints (of the back and lower extremities) and asthma. Table 2 demonstrates the diagnosed comorbidities and outcome at the end of follow-up. Diabetes and dyslipidemia did not occur while hypertension in two subjects resolved with weight loss. 
Paulus et al.: Long-Term Follow-Up Is Essential to Assess Outcome of Gastric Banding

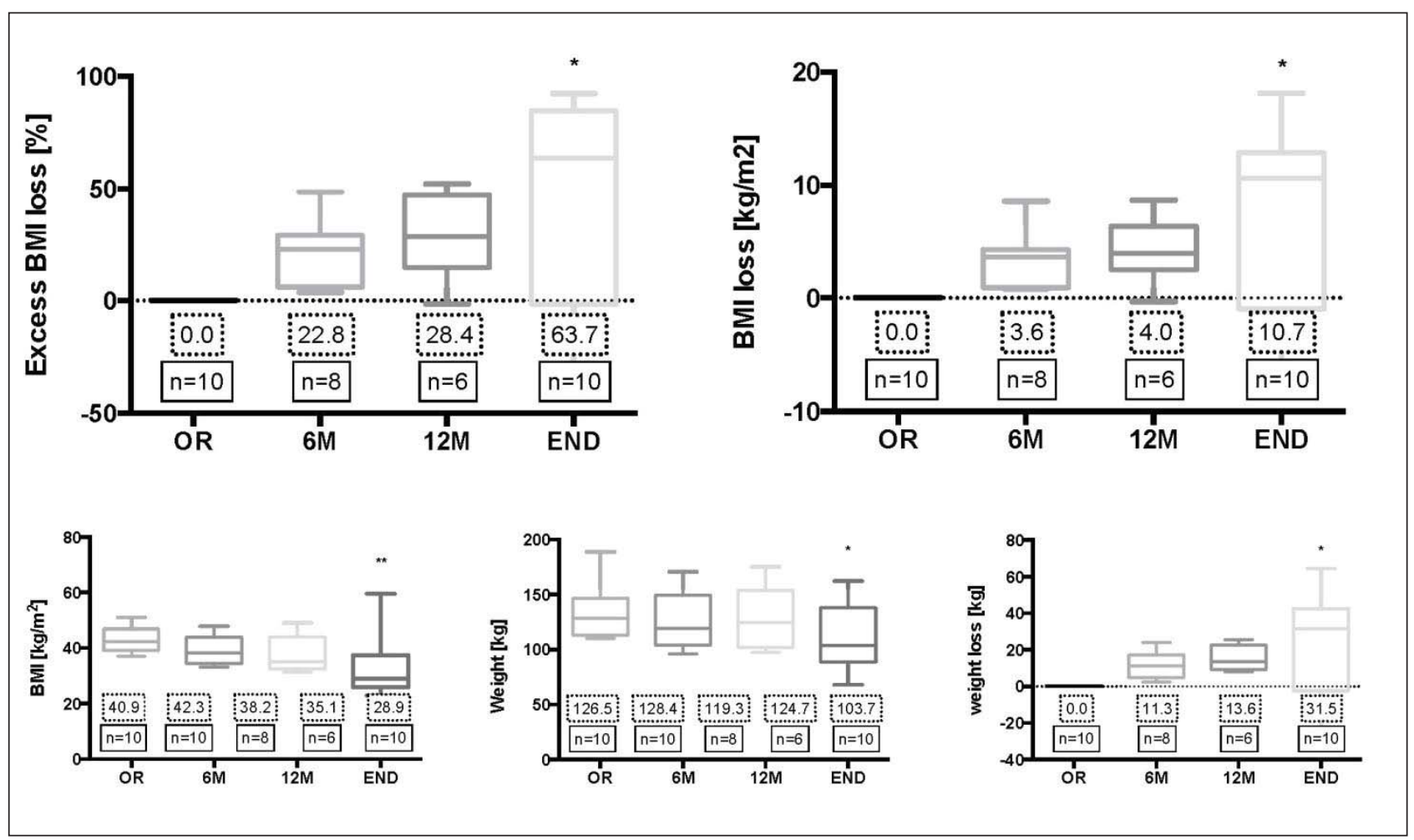

Fig. 1. Weight loss graphs expressing excess BMI loss, BMI loss, BMI, weight and weight loss in the first year and at the end of follow-up with in situ LAGB. True median values are in the dotted boxes. OR = time of procedure. $6 \mathrm{M}=6$ months follow-up. $12 \mathrm{M}=12$ months follow-up. END = last visit with gastric band in situ * p < $0.05^{* *} \mathrm{p}<0.01$ compared to OR.

Table 2. Comorbidity

\begin{tabular}{|c|c|c|c|c|c|c|c|}
\hline & \multicolumn{3}{|c|}{ Pre-operative } & \multicolumn{4}{|c|}{ End of follow-up } \\
\hline & + & - & NR & resolved & improved & unchanged & NR \\
\hline Hypertension $^{\mathrm{a}}$ & 2 & 8 & 0 & 2 & - & - & - \\
\hline $\mathrm{T} 2 \mathrm{DM}^{\mathrm{b}}$ & 0 & 10 & 0 & - & - & - & - \\
\hline Dyslipidemia $^{c}$ & 0 & 7 & 3 & - & - & - & - \\
\hline Musculoskeletal complaints & 10 & 0 & 0 & 4 & 1 & 2 & 3 \\
\hline Asthma / dyspnea & 7 & 2 & 1 & 1 & 4 & - & 2 \\
\hline
\end{tabular}

$\mathrm{NR}=$ not reported.

aHypertension: diastolic $>140 \mathrm{~mm} \mathrm{Hg}$ or systolic $>90 \mathrm{~mm} \mathrm{Hg}$.

${ }^{\mathrm{b}+\mathrm{c}}$ Dyslipidemia: total cholesterol $>6.4 \mathrm{mmol} / \mathrm{l}$, HDL cholesterol $<0.9 \mathrm{mmol} / \mathrm{l}$, LDL cholesterol $>4.4$ mmol/l or triglycerides $>1.94 \mathrm{mmol} / \mathrm{l}$.

bT2DM: HbA1C > 6.25 or $>44 \mathrm{mmol} / \mathrm{mol} \mathrm{Hb}$, fasted glucose $>7.0 \mathrm{mmol} / \mathrm{l}$.

\section{Questionnaires}

Three patients were not willing to visit our clinic for follow-up in the last year and were therefore unable to complete any questionnaires. The results of the remaining 7 patients and the baseline results are presented below. 
Fig. 2. Subscale scores on the SF36 quality of life questionnaire at the end of follow-up. Median values are presented in the dotted boxes. The red dotted bars indicate the Dutch population mean. The blue dashed bars indicate one standard deviation below mean. $\mathrm{PF}=$ Physical functioning; RP = role physical; $\mathrm{BP}=$ bodily pain; $\mathrm{GH}$ = general health; VT = vitality; $\mathrm{SF}=$ social functioning; $\mathrm{RE}=$ role emotional; $\mathrm{MH}=$ mental health.

Paulus et al.: Long-Term Follow-Up Is Essential to Assess Outcome of Gastric Banding in Morbidly Obese Adolescents: A Retrospective Analysis

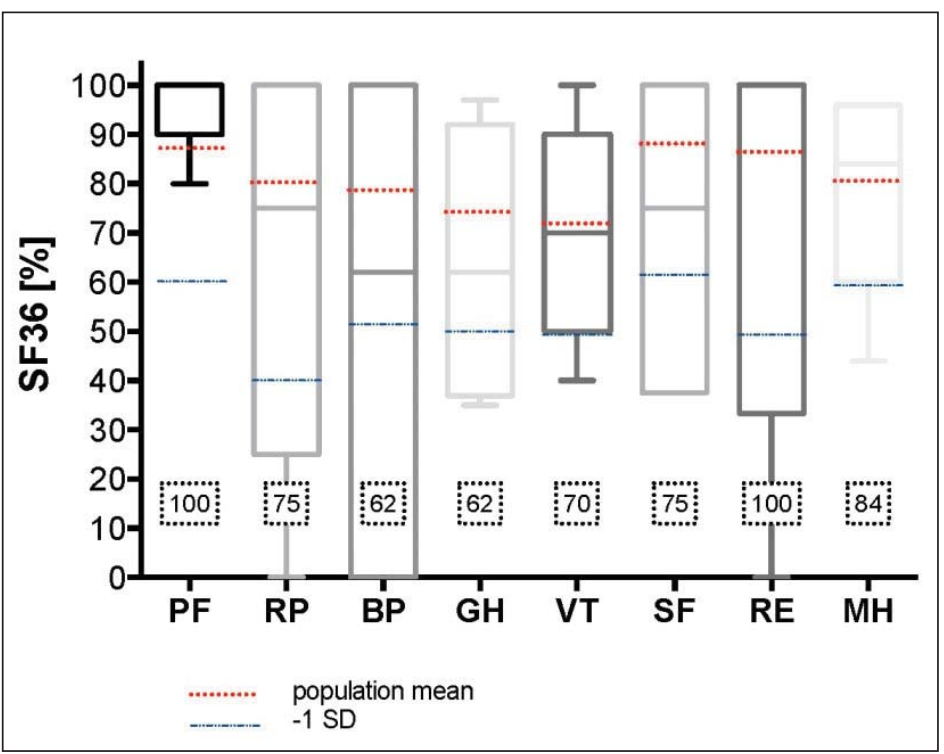

\section{Reported Health Status}

Figure 2 represents the scores on the subscales of the SF-36 health status questionnaire with Dutch population references. The median score is within the mean \pm 1 SD reference for all factors, but two subjects consistently score below the -1 SD reference on 5 or 6 subscales. Both low-scorers are male, still have a gastric band, and lost 59 and $92 \%$ excess BMI, respectively. All but 1 patient, including these 2 , reported that they would have opted for LAGB at this young age again.

\section{Eating Behavior}

Preoperative EDE-Q was available in 8 and NVE in 9 patients. Six patients had completed the questionnaires both before and after the procedure. There were no statistically significant differences in any of the subscales (fig. 3). Patients score particularly high on the weight and shape concern scales of the EDE-Q when compared to norm scores for a normal-weight population. Although weight concern on the EDE-Q shows the most substantial decrease, the change did not reach statistical significance $(p=0.07)$.

\section{Personality Traits}

Three patients completed the NPV at preoperative screening, while 5 younger patients completed the NPV-J. Preoperative scores for neuroticism, social anxiety, and dominance are therefore available for 8 patients. There was no consistency in low or high scoring for neuroticism or social anxiety, nor was there any consistent change (fig. $4 \mathrm{a}, \mathrm{b}$ ). There was however a change for dominance. Preoperatively, $5 / 7$ subjects scored below average, but all subjects had increased scores at the latest follow-up $(2 / 7$ average, 5 above, fig. $4 c$, BL vs. END p < 0.05).

\section{Discussion}

LAGB led to successful weight loss ( $>50 \%$ excess weight reduction) in 6 out of 10 patients after a median follow-up of 64 months. The length of follow-up in this study was crucial. Most weight loss was not achieved in the first postoperative year but after that. The first band 
Paulus et al.: Long-Term Follow-Up Is Essential to Assess Outcome of Gastric Banding

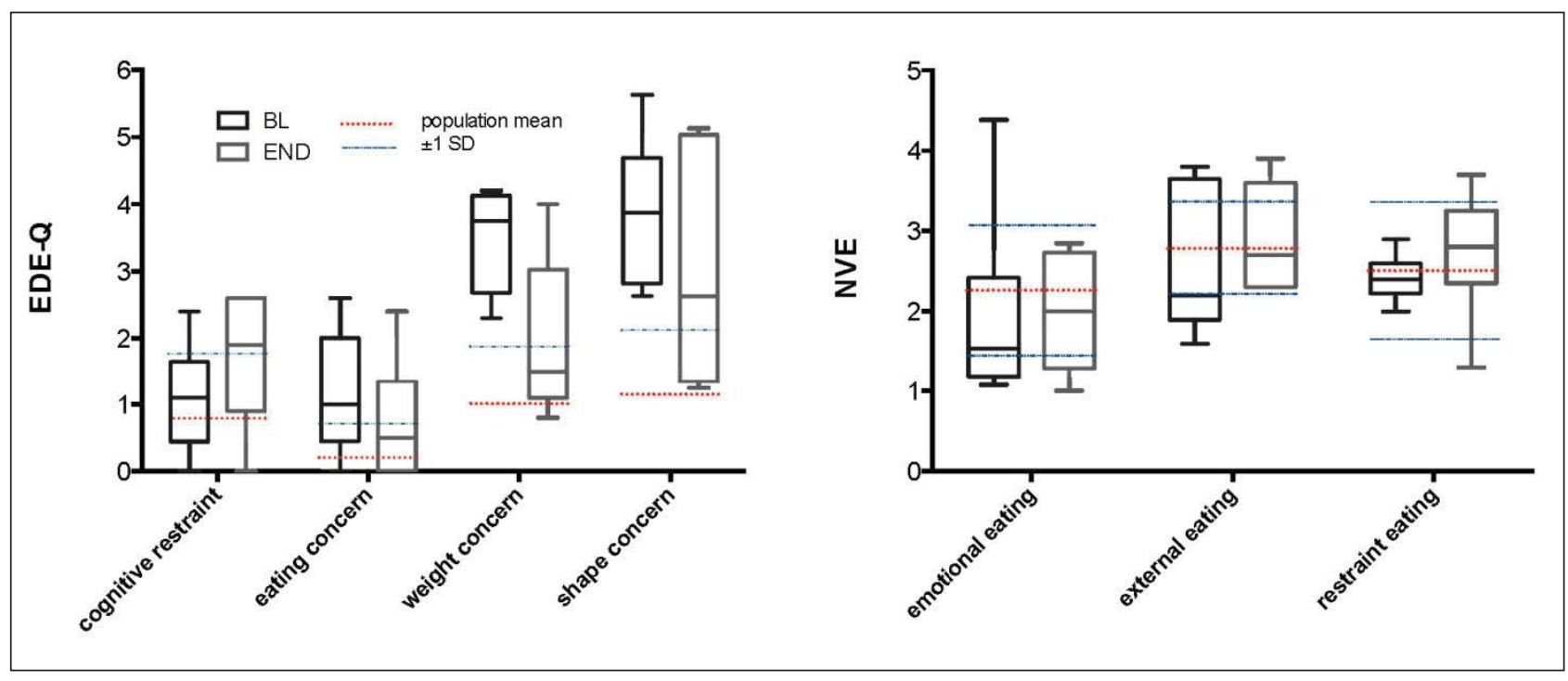

Fig. 3. Subscale scores on the EDE-Q and NVE. Baseline (BL) scores are compared to end of follow-up, with or without gastric band in situ (END). The red dotted bars indicate the Dutch population mean. The blue dashed bars indicate one standard deviation above or below the mean.

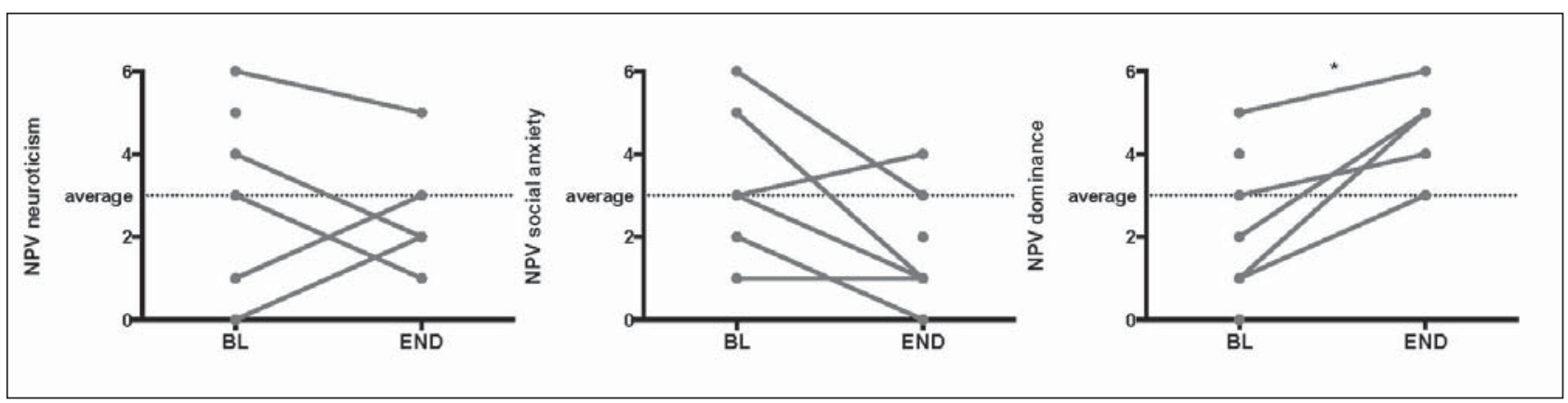

Fig. 4. Neuroticism, social anxiety and dominance as scored on the NPV and/or NPV-J before surgery (BL) and at the last follow-up visit, with or without gastric band in situ (END). *END versus BL p.

desufflation was done after 2 years, while after 3.5 years the first gastric band was removed. So had we studied this group after 2 or 3 years, the results would have been very different. Comorbidity before surgery, which was mostly limited to musculoskeletal and asthmatic complaints, showed resolution or improvement in most patients. There was 1 patient with adequate weight loss in whom the band was removed because of adverse effects. This patient remained at a stable - healthy - weight while studies in adults have shown that band removal is strongly associated with rapid weight regain [18]. We hypothesize that in this young individual restrictive bariatric surgery may have led to a permanently adjusted lifestyle and behavior towards food, since it is generally accepted that behavior changes are easier at younger age. Two patients in whom inadequate weight loss was achieved with LAGB successfully lost weight after conversion to a malabsorptive procedure. These procedures were however associated with more severe adverse effects, including two corrective procedures for internal hernia, a serious complication known to be associated with RYGB [19]. 
Paulus et al.: Long-Term Follow-Up Is Essential to Assess Outcome of Gastric Banding in Morbidly Obese Adolescents: A Retrospective Analysis

The reported physical and mental health status after LAGB is well within the Dutch population norms in 5 out of 7 patients. The 2 patients who perceived low mental and physical health status had successful weight loss and reported to be satisfied with their gastric band. However, one is struggling with body image and applied for corrective surgery, and the other was recently released from prison, which probably influences wellbeing more than the results of gastric banding.

Since bariatric surgery in adolescents was very exceptional at that time, and still is in the Netherlands, only a small group of patients could be included. There were no significant changes in eating behavior after LAGB. However, even in this small group, weight concern showed a decreasing trend. An interesting observation is the significant shift from a low dominant personality score to a higher score for all patients. The items involved in dominance relate to taking initiative, leadership, and confidence in a group. A low score on hostility, a scale reflecting criticism to others and distrust, seemed to be in line. However, low scores were also observed for self-esteem. Overall, the scores on the NPV reflected gained trust in positioning oneself towards others and feeling confident in contact with others, while still having a relatively low self-image. Whether this change was attributable to weight loss, aging or both cannot be concluded without a control group.

Despite well-organized preoperative evaluation and postoperative follow-up, there is missing data due to poor reporting and 30\% loss to follow-up in the past year. Still, follow-up in this study is longer than the vast majority of the available literature. A recent review found only one long-term retrospective LAGB study with more than 36 months follow-up in adolescents [6]. Meta-analysis of all eligible studies showed a BMI reduction of $11.6 \mathrm{~kg} / \mathrm{m}^{2}$ while the long-term study by Silberhumer et al. [20] showed BMI loss of $18.1 \mathrm{~kg} / \mathrm{m}^{2}(93 \%$ excess weight loss) after 60 months follow-up. They showed that most of the weight loss occurred in the first 3 years while most complications occurred afterwards, which is in line with what was found in the present study.

Gastric banding is losing popularity in adults compared to sleeve gastrectomy and RYGB as the bariatric procedure of choice, but it carries definite advantages. It is the procedure with the lowest operative risk, and it is effective in the majority of patients. It does not alter gastrointestinal anatomy and is completely reversible. When weight loss is unsuccessful, a malabsorptive procedure as a second step seems a feasible and effective option for those who failed.

\section{Conclusion}

LAGB in morbidly obese adolescents had a primary failure rate of $40 \%$ after long-term follow-up, but was a successful therapy in the other $60 \%$ without major adverse events. Conversion to malabsorptive procedures after unsuccessful weight loss was effective but associated with complications related to their invasiveness. We strongly encourage studies to continue follow-up for at least 5 years and to look at both weight loss and complications with the gastric band in situ and after conversion to more invasive procedures. Larger prospective studies should provide more insight in changed eating behavior and personality.

\section{Acknowledgements}

We thank Bernadette van Velzen for her support in analyzing the questionnaires. 
Paulus et al.: Long-Term Follow-Up Is Essential to Assess Outcome of Gastric Banding in Morbidly Obese Adolescents: A Retrospective Analysis

\section{Grant Support}

There was no grant support.

\section{Disclosure Statement}

The authors declare that they have no conflict of interest.

\section{References}

1 Ogden CL, Carroll MD, Kit BK, Flegal KM: Prevalence of obesity and trends in body mass index among US children and adolescents, 1999-2010. JAMA 2012;307:483-490.

2 Rocchini AP Childhood obesity and coronary heart disease. N Engl J Med 2011;365:1927-1929.

-3 Juonala M, Magnussen CG, Berenson GS, Venn A, Burns TL, Sabin MA, Srinivasan SR, Daniels SR, Davis PH, Chen W, Sun C, Cheung M, Viikari JS, Dwyer T, Raitakari OT: Childhood adiposity, adult adiposity, and cardiovascular risk factors. N Engl J Med 2011;365:1876-1885.

4 Russell-Mayhew S, McVey G, Bardick A, Ireland A: Mental health, wellness, and childhood overweight/obesity. J Obes 2012;2012:281801.

5 Oude Luttikhuis H, Baur L, Jansen H, Shrewsbury VA, O'Malley C, Stolk RP, Summerbell CD: Interventions for treating obesity in children. Cochrane Database Syst Rev 2009;1:CD001872.

-6 Paulus GF, de Vaan LE, Verdam FJ, Bouvy ND, Ambergen TA, van Heurn LW: Bariatric surgery in morbidly obese adolescents: a systematic review and meta-analysis. Obes Surg 2015;25:860-878.

7 Aarts E, Koehestanie P, Dogan K, Berends F, Janssen I: Revisional surgery after failed gastric banding: results of one-stage conversion to RYGB in 195 patients. Surg Obes Relat Dis 2014;10:1077-1083.

-8 van Strien T, Herman CP, Verheijden MW: Eating style, overeating, and overweight in a representative Dutch sample. Does external eating play a role? Appetite 2009;52:380-387.

-9 Braet C, Claus L, Goossens L, Moens E, Van Vlierberghe L, Soetens B: Differences in eating style between overweight and normal-weight youngsters. J Health Psychol 2008;13:733-743.

10 Snoek HM, van Strien T, Janssens JM, Engels RC: Emotional, external, restrained eating and overweight in Dutch adolescents. Scand J Psychol 2007;48:23-32.

11 Jokela M, Hintsanen M, Hakulinen C, Batty GD, Nabi H, Singh-Manoux A, Kivimäki M: Association of personality with the development and persistence of obesity: a meta-analysis based on individual-participant data. Obesity Rev 2013;14:315-323.

12 Dargent J: Pouch dilatation and slippage after adjustable gastric banding: is it still an issue? Obes Surg 2003; 13:111-115.

13 Aaronson NK, Muller M, Cohen PD, Essink-Bot ML, Fekkes M, Sanderman R, Sprangers MA, te Velde A, Verrips E: Translation, validation, and norming of the Dutch language version of the SF-36 Health Survey in community and chronic disease populations. J Clin Epidemiol 1998;51:1055-1068.

14 van Strien, T, Frijters, JER, Bergers, GPA, Defares, PB: The Dutch Eating Behavior Questionnaire (DEBQ) for assessment of restrained, emotional, and external eating behavior. Int J Eat Disord 1986;5:295-315.

15 Fairburn CG, Cooper Z: The eating disorder examination (12th ed.); in Fairburn CG, Wilson GT (eds): Binge Eating: Nature, Assessment and Treatment. New York, Guilford Press, 1993, pp 317-360.

16 Luteijn F, Starren J, Dijk H, Van Dijk H: Manual for the Dutch Personality Questionnaire, Revised Edition (in Dutch). Lisse, Swets \& Zeitlinger, 2000.

17 F. Luteijn F, Van Dijk H, Barelds DPH: NPV-J Nederlandse PersoonlijkheidsVragenlijst Junior, herziene Handleiding 2005. Enschede, Harcourt Test Publishers, 2005.

18 Lanthaler M, Strasser S, Aigner F, Margreiter R, Nehoda H: Weight loss and quality of life after gastric band removal or deflation. Obes Surg 2009;19:1401-1408.

19 Elms L, Moon RC, Varnadore S, Teixeira AF, Jawad MA: Causes of small bowel obstruction after Roux-en-Y gastric bypass: a review of 2,395 cases at a single institution. Surg Endosc 2014;28:1624-1628.

20 Silberhumer GR, Miller K, Pump A, Kriwanek S, Widhalm K, Gyoeri G, Prager G: Long-term results after laparoscopic adjustable gastric banding in adolescent patients: follow-up of the Austrian experience. Surg Endosc 2011;25:2993-2999. 